\title{
The Effect of MgO Dopant and Laser Treatment on ZnO Ceramic
}

\author{
Fadhil A. Chyad ${ }^{1}$, Shaymaa Q. Abul Hassan ${ }^{2}$, Zyad T. Al-Dahan ${ }^{3}$ \\ ${ }^{1}$ Department of Materials Engineering, University of Technology, Baghdad, Iraq \\ ${ }^{2}$ Department of Physics, College of Ibn-Al-Haithm, Baghdad University, Baghdad, Iraq \\ ${ }^{3}$ College of Engineering, University of Al-Nahrian, Baghdad, Iraq \\ Email: fchyad_2009@yahoo.de
}

Received September 18, 2013; revised October 26, 2013; accepted November 6, 2013

Copyright (C) 2013 Fadhil A. Chyad et al. This is an open access article distributed under the Creative Commons Attribution License, which permits unrestricted use, distribution, and reproduction in any medium, provided the original work is properly cited.

\begin{abstract}
$\mathrm{ZnO}$ ceramic samples as pellets have been prepared and doped with $(1,2.5,5,10 \mathrm{wt} \%)$ of $\mathrm{MgO}$ powder, sintering at $1300^{\circ} \mathrm{C}$, these samples have been treated with laser at $400 \mathrm{~J} / \mathrm{cm}^{2}$. X-ray diffraction spectra of the samples show some changes in the X-ray parameters, where d-spacing and the intensities of the peaks are changed. FWMH of all the samples was altered due to $\mathrm{MgO}$ dopant and the laser influence microstructure was affected by the laser treatment, also, the texture coefficient is affected.
\end{abstract}

Keywords: ZnO; Laser Treatment; Texture Coefficient; FWMH; X-Ray Diffraction

\section{Introduction}

Ceramic is an important class of materials which finds increased applications as biomaterials, advanced structural and engineering materials, where surface modifications become important which were greatly influenced by the surface microstructure defined by the morphology and crystallographic texture of the surface grain [1].

$\mathrm{ZnO}$ is one of these ceramics with wide band gap semiconductors which is used in optical devices near ultraviolet region.

It has good optical, electrical and piezoelectric properties because it has high transparence in the visible wave length range and low electric resistance and its band gap is $3.3 \mathrm{eV}$ at room temperature [2].

It has been used in many applications such as gas sensors, bulk acoustic wave devices, transparent conductive oxide, solar cell windows besides its applications as biomaterials against bacteria (i.e. solution or powders for skin ointment). Many studies have been conducted on laser interaction with ceramic materials, for example, ceramics welding with laser have been studied by Ikeda [3]. For preventing crack for motion at the welded part, a preheating at slow cooling was effective.

Mordike and Sivakumar [4] have used a laser beam to locally melt and densify the ceramic coatings.

Harimkar and Dohotre [5] have discussed the micro- structure development during surface modifications of alumina ceramic using high power continuous wave Nd:YAG laser.

Krasnikov et al. [6] have been studied the effect of laser treatment with varying pulse duration and pumping voltage on ceramic material. They found the amorphazation of the ceramic structure in the laser beam action zone is established.

Ural et al. [7] have studied the effect of laser treatment on the bonding between zirconia ceramic surface and resin cement which has a clear effect on the microstructure of bonding region.

Abeidia et al. [8] have studied the realization of molted layers with the $\mathrm{CO}_{2}$ laser on sintered alumina ceramic.

Dyshlovenko et al. [9] have used $\mathrm{CO}_{2}$ laser to treat plasma sprayed hydroxylapatite coating. The laser beam was scanned with speed of $6.4 \mathrm{~mm} / \mathrm{s}$. SEM and X-ray diffraction enabled the determination of quantitative phase composition.

Dimitrov et al. [10] have used pulsed laser deposition which can provide crystallization at relatively low substrate temperature due to the higher energy of the ablated particles in the laser-produce plume and relatively high deposition rates.

Adawya et al. [11] have studied the deposition of $\mathrm{Al}_{2} \mathrm{O}_{3}$ on glass substrate by PLD in $10^{-3} \mathrm{~m}$ bar oxygen 
ambient at different alumina concentration with laser fluency energy $0.4 \mathrm{~J} / \mathrm{cm}^{2}$.

The aim of this work is to study the influence of Nd: YAG laser on the microstructure and morphology of $\mathrm{ZnO}$ ceramic with and without $\mathrm{MgO}$.

\section{Experimental Procedure}

\subsection{Materials Used}

In the present study, $\mathrm{ZnO}$ powder used was obtained from Fluka Company with $99.5 \%$ purity, and less than $25 \% \mu \mathrm{m}$ particle size $\mathrm{MgO}$ obtained from Boh Company with the purity $99.5 \%$, and $25 \mu \mathrm{m}$ particle size. PVA (poly vinyl alcohol) is used as binder.

\subsection{Equipments Used}

1) Nd:YAG laser with $400 \mathrm{~J} / \mathrm{cm}^{2}$.

2) Digital balance (0.0001 gm) sensitivity.

3) Oven type cooper heat.

4) Hydraulic press type (BeGo) capacity 5 tons.

5) Electrical furnace (Ruhs Tral Co.) up to $1350^{\circ} \mathrm{C}$.

6) X-ray diffractions type (XRD 6000 SHIMADZU JAPAN, $\lambda=1.5405 \mathrm{~A}^{\circ}$ ).

7) Optical microscope type (OLYMPUS OPTICAL Co. LTD. JAPAN).

\subsection{Samples Preparation}

$\mathrm{ZnO}$ powder mixed thoroughly with $1.5 \%$ of PVA as a binding material and pressed at 3 tons as a disc of $10 \mathrm{~mm}$ diameter and $4 \mathrm{~mm}$ thickness.

Other samples contain four percentages of $\mathrm{MgO}(1$ $\mathrm{wt} \%, 2.5 \mathrm{wt} \%, 5 \mathrm{wt} \%$ and $10 \mathrm{wt} \%)$ mixed and pressed as the same above procedure.

All the samples dried at $80^{\circ} \mathrm{C}$ in an oven for six hours and then sintered in an electrical furnace at $1300^{\circ} \mathrm{C}$ with $5^{\circ} \mathrm{C} / \mathrm{min}$ as a heating rate for $2 \mathrm{hrs}$ and then cooling at the same rate. All the samples have been treated with pulsed laser.

\section{Results and Discussion}

\subsection{Analysis of X-Ray Spectra}

Laser surface modification of $\mathrm{ZnO}$ and $\mathrm{ZnO}$ doped $\mathrm{MgO}$ ceramics with the range of laser influence $\left(400 \mathrm{~J} / \mathrm{cm}^{2}\right)$ employed in the present study.

X-ray diffraction patterns obtained at room temperature for $\mathrm{ZnO}$ sample before and after laser treatment are shown in Figures 1 and 2.

After treatment, there was a change in the intensities of the peaks with sharp altitude, also shift slightly towards high $2 \theta$ values which mean the d-spacing values are decreased.

Figures 3-10 show the $\mathrm{X}$-ray spectra of $\mathrm{ZnO}$ doped



Figure 1. XRD Spctrum of pure ZnO.

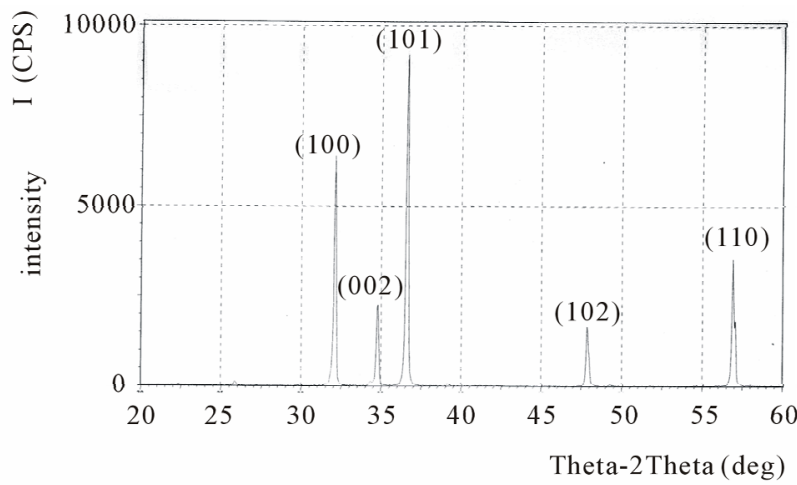

Figure 2. XRD Spctrum of treated ZnO by Laser.

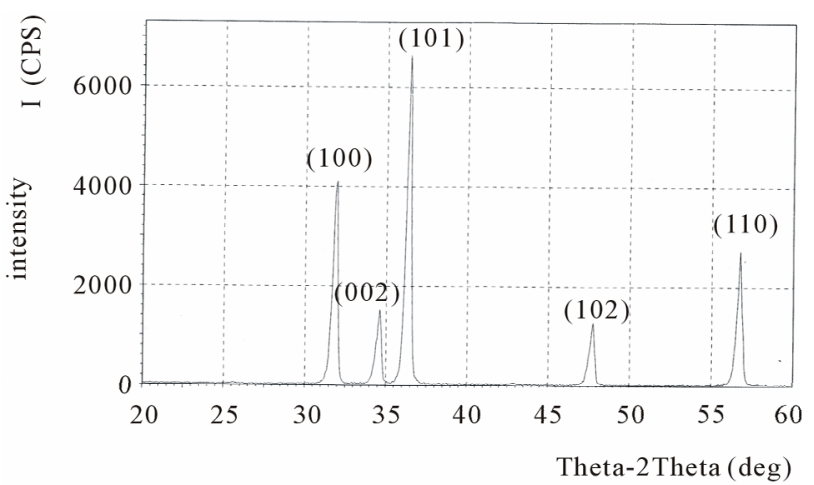

Figure 3. XRD of $\mathrm{ZnO}$ doped with $1 \mathrm{wt} \% \mathrm{MgO}$ sintered at $1300^{\circ} \mathrm{C}$.

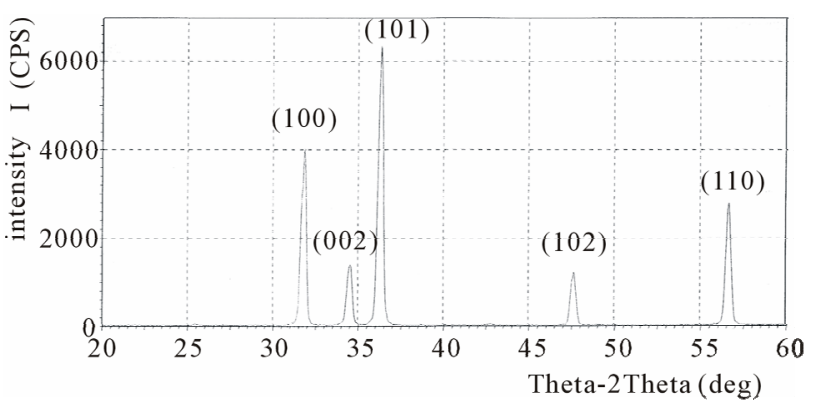

Figure 4. XRD Spectrum of ZnO 1 wt\% MgO treated by Laser. 


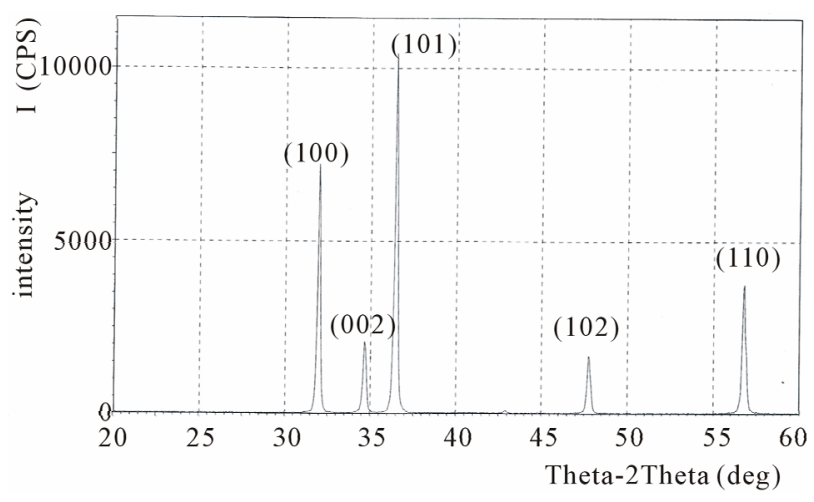

Figure 5. XRD Spectrum of ZnO 2.5 wt\% MgO.

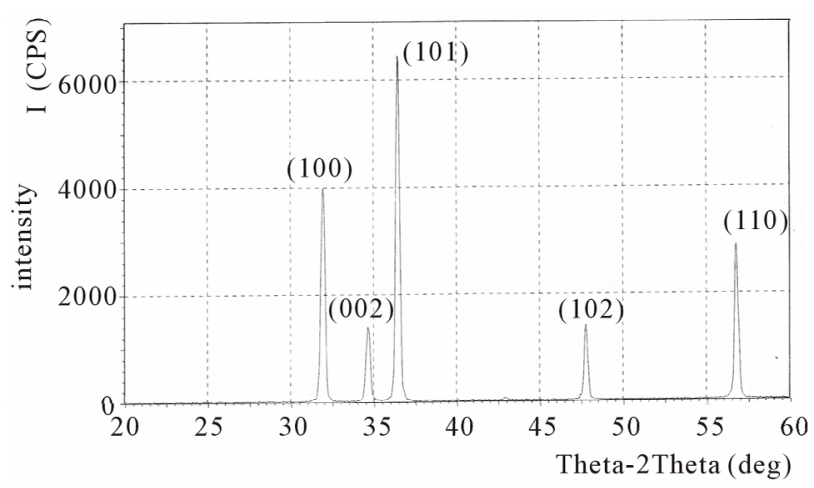

Figure 6. XRD Spectrum of treated ZnO 2.5 wt\% MgO.

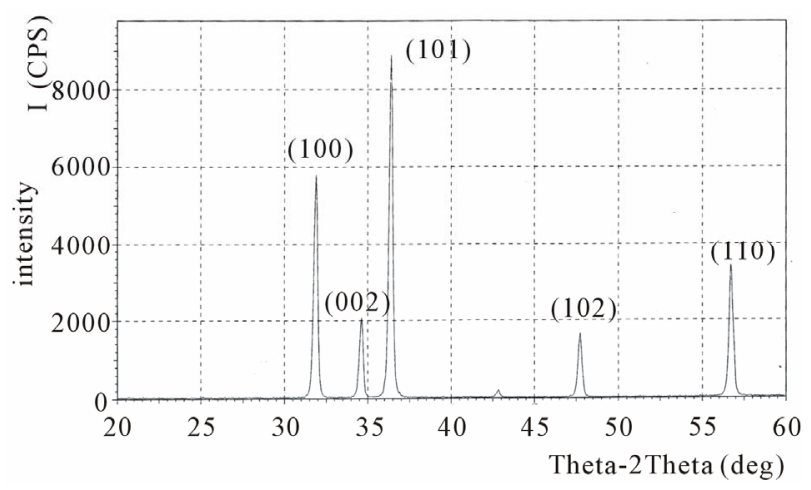

Figure 7. XRD Spectrum of ZnO 5 wt\% MgO.

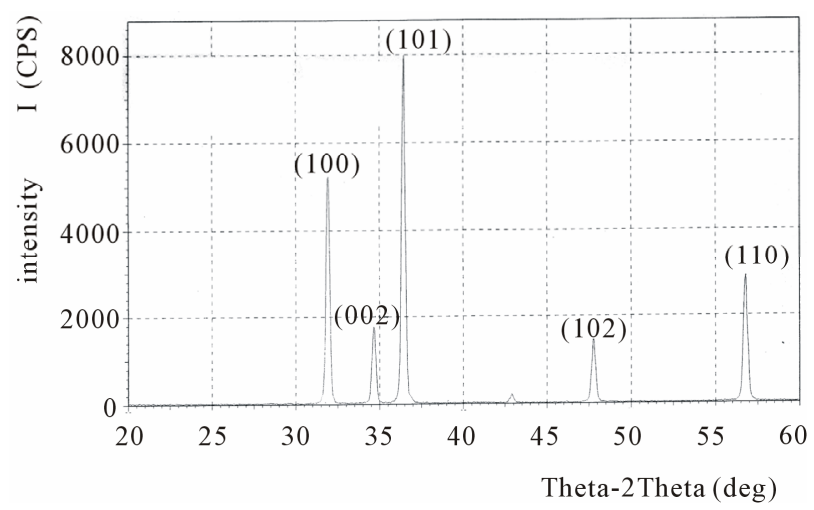

Figure 8. XRD Spectrum of treated $\mathrm{ZnO} 5 \mathrm{wt} \% \mathrm{MgO}$.

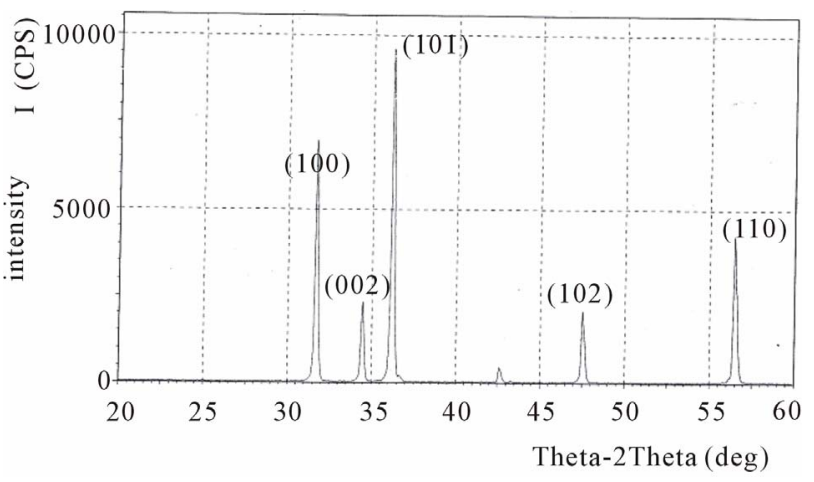

Figure 9. XRD Spectrum of ZnO 10 wt\% MgO.

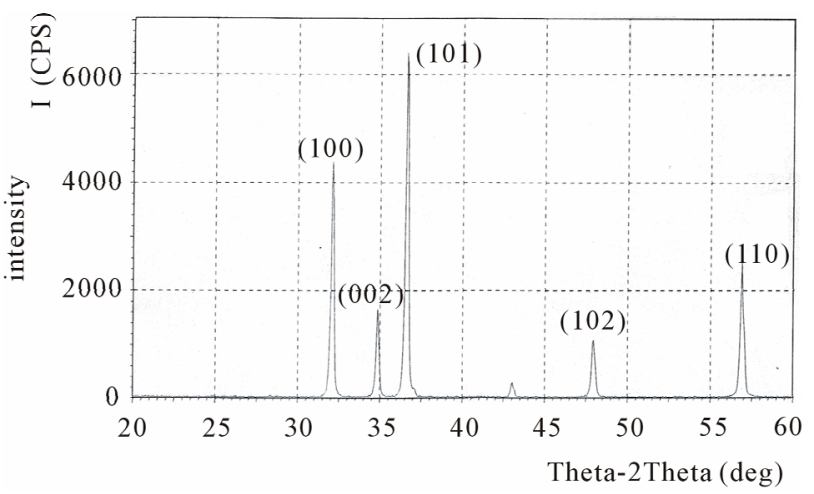

Figure 10. XRD Spectrum of ZnO 10 wt\% MgO treated by Laser.

with different percentages of $\mathrm{MgO}(1 \mathrm{wt} \%, 2.5 \mathrm{wt} \%, 5$ $\mathrm{wt} \%$ and $10 \mathrm{wt} \%$ ) before and after treatment by laser. At $1 \mathrm{wt} \% \mathrm{MgO}$ dopant it is cleared that d-spacing is increased by introducing the $\mathrm{MgO}$ oxide and the altitude of peak intensities is increased again and the d-spacing values decreased at the laser treatment, but still higher than those of pure $\mathrm{ZnO}$ as shown in Figure 4.

At $2.5 \mathrm{wt} \% \mathrm{MgO}$ again sharp and high altitude of peaks have shown with decreasing in d-spacing but after treatment with laser the change in d-spacing values are small with sharp peaks as shown in Figure 6.

Increasing the doping to $5 \mathrm{wt} \% \mathrm{MgO}$ high peaks intensities observed and the d-spacing values are decreased sharply as shown in Figure 7. Figure 8 shows the spectra of laser treatment of the samples have sharp peaks and high intensities are observed with decreasing in dspacing values.

A small intensity peak at $2 \theta$ equal 43.04 appeared in this spectra which is belong to $\mathrm{MgO}$ according to $\mathrm{N} 1997$ JCPAS No. 45-0946.

Figure 9 shows the spectra of $10 \mathrm{wt} \% \mathrm{MgO}$ which has very sharp peak with high intensity and high d-spacing values, but at the treatment with laser the intensities are decreased slightly with decreasing of d-spacing values, a new peak with $2 \theta$ equal 42.63 which belong to $\mathrm{MgO}$ observed with slight high intensity in Figure 10. 
In general, the analysis of X-ray spectra revealed a systematic variation of relative intensities and d-spacing values for all the spectra planes with $\mathrm{MgO}$ dopant and laser influence.

\subsection{Analysis of Texture Coefficient}

Figure 11 shows the values of FWHM for all the samples which show that the addition of $\mathrm{MgO}$ is increased the value of FWHM and the maximum is at $1 \mathrm{wt} \%$ and then decreased, with treated the samples by laser the value of pure $\mathrm{ZnO}$ is increased and the same behavior with the doping of $\mathrm{MgO}$.

The development of texture with the laser influence can be quantified in terms of the texture coefficient (TC) given by [3]:

$$
T c(h k l)=\frac{I(h k l)}{I_{0}(h k l)}\left\{\frac{1}{n} \sum \frac{I(h k l)}{I_{0}(h k l)}\right\}^{-1}
$$

where $I(h k l)$ are measured intensities of $(h k l)$ reflection, $I_{\mathrm{o}}(h \mathrm{kl})$ are powder reflection intensities of $\mathrm{ZnO}$ according to ICDD PDF $\neq 36-1451$ and $(n)$ is the number of reflections used in the calculation.

Following $(h \mathrm{kl})$ reflections corresponding (100,002, $101,102,110)$ of the samples the results of TC calculation for (100) reflection are presented in Figure 12.

The figure indicates that the TC increased gradually with increasing $\mathrm{MgO}$ content which reached maximum value at $2.5 \mathrm{wt} \%$ and then decreased progressively; thus substantiating the formation of strong (100) texture at the intermediate $\mathrm{MgO}$ content, these two regimes of explored $\mathrm{MgO}$ contained less and greater than $2.5 \mathrm{wt} \%$. The variation of TCs and the relative intensity of (100) plane corresponding closely with the regimes of $\mathrm{MgO}$ content and laser influence which showed a distinct variation in the morphology of surface grains in laser surface modified $\mathrm{ZnO}$ ceramic as shown in Figure 12.

\subsection{Analysis of Microstructures}

The effect of laser irradiation on the surface microstructure of $\mathrm{ZnO}$ and $\mathrm{ZnO}$ doped $\mathrm{MgO}$ are illustrated in Figures 13-17. These figures present a set of optical surface images which represent the untreated and treated samples at laser influence of $400 \mathrm{~J} / \mathrm{cm}^{2}$.

The untreated samples consisted of irregular $\mathrm{ZnO}$ and $\mathrm{MgO}$ grains with a degree of interconnected porosity.

It is evident that the surface microstructure of laser modified $\mathrm{ZnO}$ ceramic is characterized by faceted polygonal surface grains with varying size and the extension of surface faceting depend on $\mathrm{MgO}$ contend and laser influence.

Some of the surface grains tend to deviate from polygonal shapes transferred from irregular to near circular shapes.

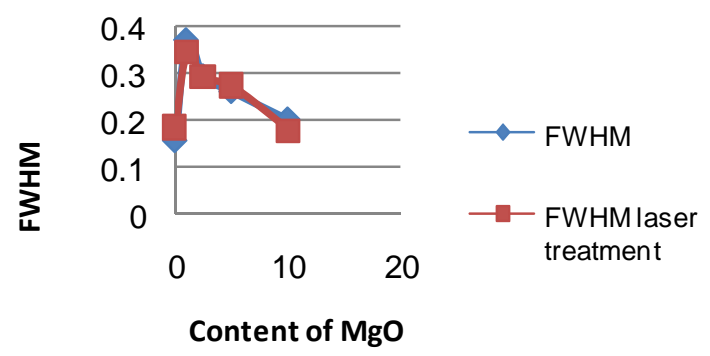

Figure 11. Variation of (100) FWHM of untreated and treated samples with laser influences.

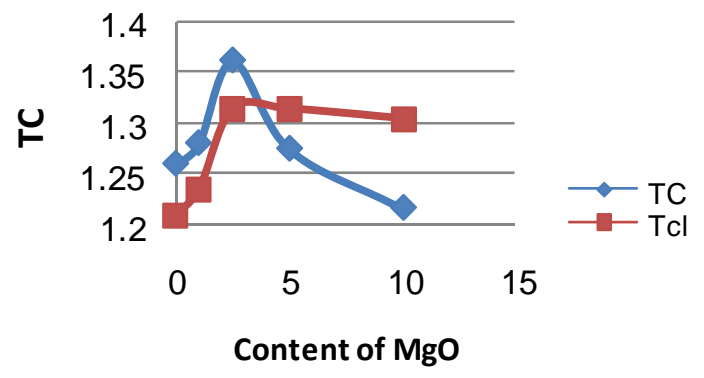

Figure 12. Variation of (100) TC of untreated and treated samples with laser influences.

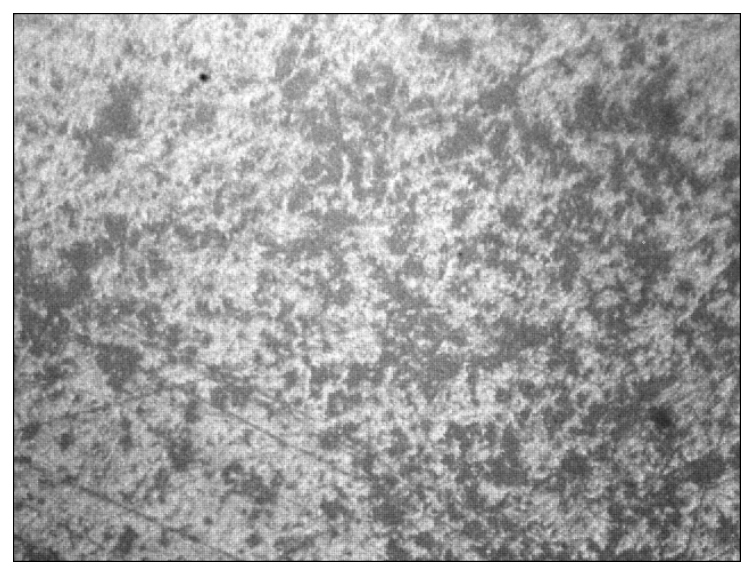

(a)

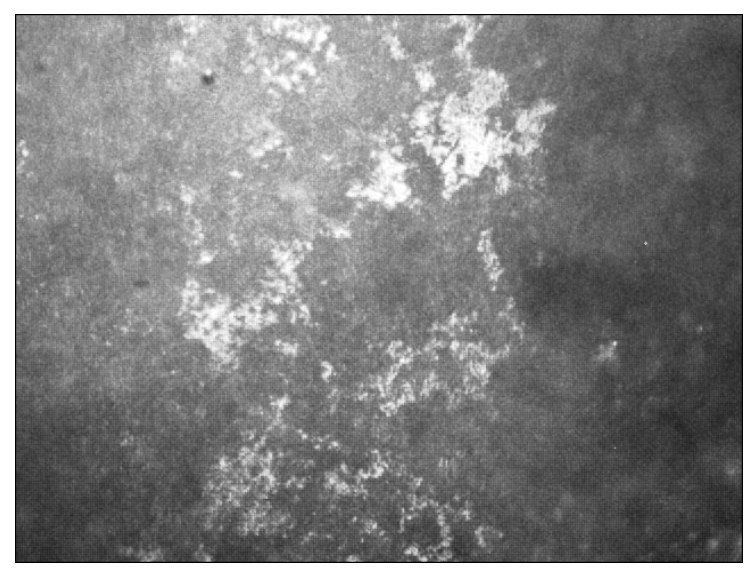

(b)

Figure 13. Micrograph optical microscope of (a) untreated and (b) laser treated of pure $\mathrm{ZnO}$. 


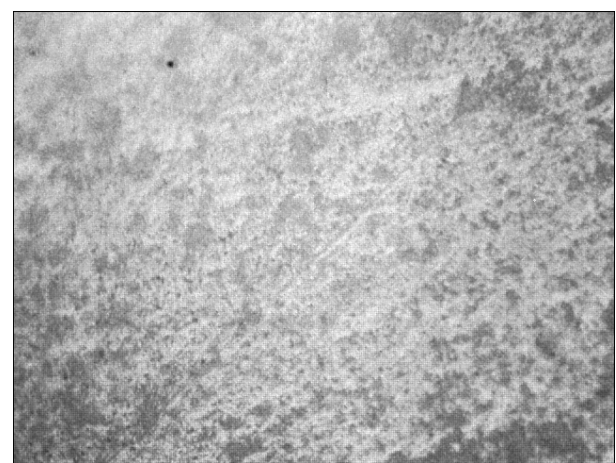

(a)

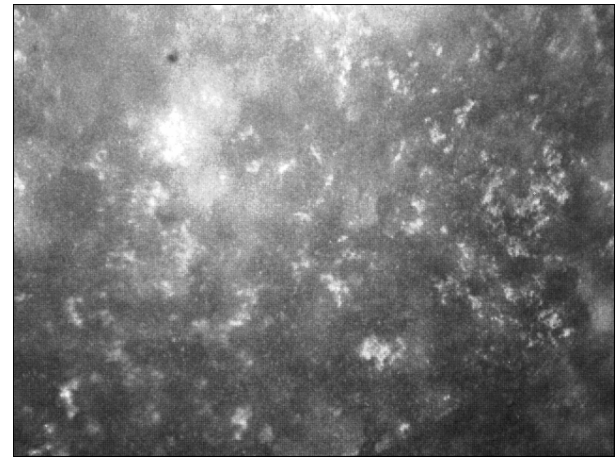

(b)

Figure 14. Micrograph optical microscope of (a) untreated and (b) laser treated of $\mathrm{ZnO}$ with $1 \mathrm{wt} \% \mathrm{MgO}$.



(a)

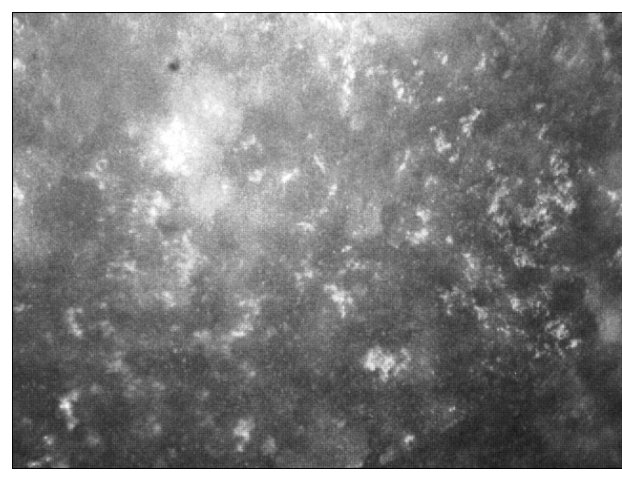

(b)

Figure 15. Micrograph optical microscope of (a) untreated and (b) treated $\mathrm{ZnO}$ with $2.5 \mathrm{wt} \% \mathrm{MgO}$.

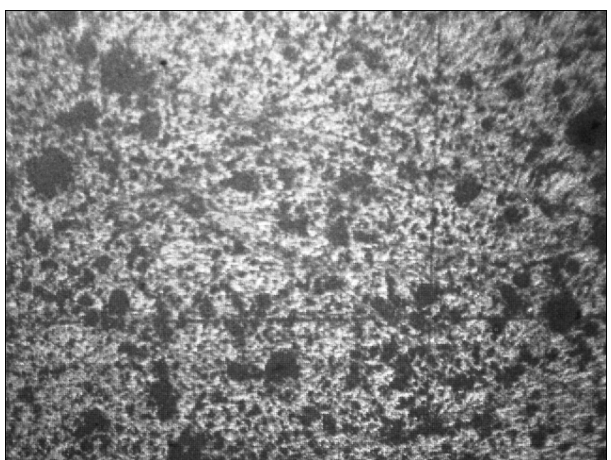

(a)

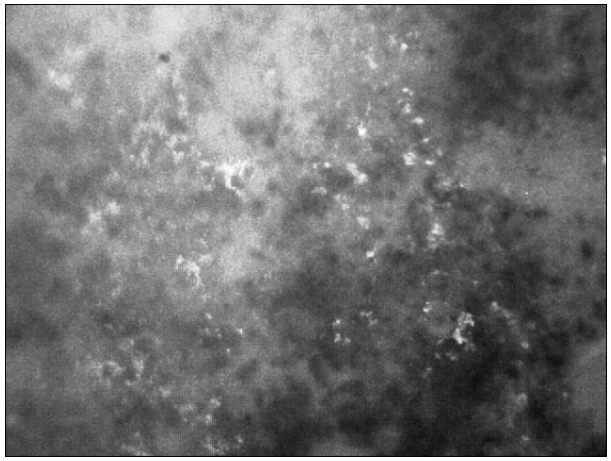

(b)

Figure 16. Micrograph optical microscope of (a) untreated and (b) laser treated of $\mathrm{ZnO}$ with $5 \mathrm{wt} \% \mathrm{MgO}$.

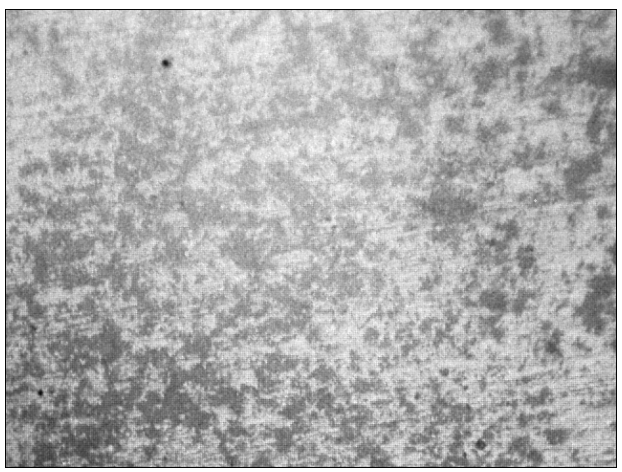

(a)



(b)

Figure 17. Micrograph optical microscope of (a) untreated and (b) laser treated of $\mathrm{ZnO}$ with $10 \mathrm{wt} \% \mathrm{MgO}$. 


\section{Conclusions}

Laser surface modifications of $\mathrm{ZnO}$ ceramic and $\mathrm{ZnO}$ doped with different percentages of $\mathrm{MgO}$ with Nd-YAG laser results in the formation of surface microstructure consisted of faceted surface grain have been observed.

$\mathrm{MgO}$ dopant and laser influence have changed the parameters of microstructure of $\mathrm{ZnO}$ such as FWHM, dspacing, $2 \theta$ and intensities of the peaks besides the texture coefficient (TC)n.

\section{REFERENCES}

[1] F. K. Shan and Y. S. Yu, "Optical Properties of Pure and Al Doped ZnO Thin Films Fabricated with Plasma Produced by Excimer Laser," Thin Solid Films, Vol. 435, No. 1-2, 2003, pp. 174-178.

[2] A. Ashida, H. Ohta, J. Nagata and T. Ito, "Optical Propagation Loss of $\mathrm{ZnO}$ Films Grown on Sapphire," Journal of Applied Physics, Vol. 95, No. 4, 2004, pp. 1673-1676.

[3] M. Iked, "Ceramics Welding with Laser," Taikabutsu Overseas, Vol. 5, No. 3, 1985, pp. 27-33.

[4] B. 1. Mordike and R. Sivakumar, "Laser Treatment of Materials," DGM Information Sgesell Schaft, Oberursel, 1987, p. 373.

[5] S. P. Harimkar and N. B. Dabotre, "Evolution of Surface Morphology in Laser-Dressed Alumina Grinding Wheel
Material," International Journal of Applied Ceramic Technology, Vol. 3, No. 5, 2006, pp. 375-381.

[6] A. Krasnikov, A. Berezhnoi and L. Mrkim, "Structure and Properties of Ceramic Material after Laser Treatment," Glass and Ceramic, Vol. 56, No. 5-6, 1999, pp. 172-176.

[7] C. Ural, T. Kulunk, S. Kulunk and M. Kurt, "The Effect of Laser Treatment on Bonding between Zirconia Ceramic Surface and Resin Cement," Acta Odontologica Scandinavica, Vol. 68, No. 6, 2010, pp. 354-359. http://dx.doi.org/10.3109/00016357.2010.514720

[8] H. Abeidia, A. Issa, M. Robin and G. Faniossi, "Realization of Melted Layers with $\mathrm{CO}_{2}$ Laser on Sintered Ceramic," Journal de Physique IV, Vol. 1, No. C7, 1991, pp. 39- 42.

[9] S. Dyshlovenko, L. Pawlowski, I. Smurove and V. Veiko, "Pulsed Laser Modification of Hydroxylapatite Ceramic," Surface and Coatings Technology, Vol. 201, 2006, pp. 22482255.

[10] J. G. Dimitrov, P. A. Atanasov and T. Vasiler, "Al-Doped $\mathrm{ZnO}$ Thin Films for Gas Sensor Application," Journal of Physics: Conference Series, Vol. 113, 2008, Article ID: 012044.

[11] J. H. Adawiya, et al., "Effect of Alumina-Doping Structural and Optics Properties of ZnO Thin Film by Pulsed Laser Deposition," Journal of Engineering \& Technology, Vol. 28, No. 14, 2010, pp. 4677-4686. 